\title{
Salud y Orgullo Mexicano: Development of a Culturally Specific Transnational Linkage and Retention in Care Intervention for Mexican Men Who Have Sex with Men Living with HIV in Chicago
}

\author{
Amy K. Johnson ${ }^{1,2,3}$ (D) $\cdot$ Román Buenrostro ${ }^{3} \cdot$ Gilberto Soberanis $^{3} \cdot$ Banita McCarn $^{3} \cdot$ Bridget Magner $^{4}$. \\ Andres Maiorana 5
}

Accepted: 10 March 2021

(c) The Author(s) 2021

\begin{abstract}
This manuscript documents the development of an innovative individual-level peer navigation intervention "Salud y Orgullo Mexicano" (SOM) designed to increase linkage and retention to HIV care for Mexican men who have sex with men (MSM) in Chicago, Illinois. The intervention was developed via a modified intervention mapping process. Elements of two existing interventions were combined and refined with input from the Mexican MSM community, including informant interviews, an expert advisory board, and a design team. A manualized transnational intervention was developed via intervention mapping. A peer health navigation intervention "SOM" was created using intervention mapping and input from the focus community. Next steps include implementing and evaluating the intervention to determine acceptability and efficacy.
\end{abstract}

Keywords HIV care - Intervention implementation · Mexican men who have sex with men · Peer health navigation · Engagement and retention in care

\section{Introduction}

Latinos in the United States are disproportionately affected by HIV having the second highest rate of diagnoses of all racial/ethnic groups and nearly three times the rate for nonHispanic whites $[1,2]$. While men who have sex with men (MSM) comprise only $2 \%$ of the population, they accounted for almost $70 \%$ of new HIV diagnoses in the United States in 2016 [3]. Latino MSM in the United States are

Amy K. Johnson

akjohnson@luriechildrens.org

1 Department of Pediatrics, Division of Adolescent Medicine, Ann and Robert H. Lurie Children's Hospital of Chicago, 225 E. Chicago Avenue, Box 161, Chicago, IL 60611-2991, USA

2 Department of Pediatrics, Feinberg School of Medicine, Northwestern University, Chicago, IL, USA

3 AIDS Foundation of Chicago, Chicago, IL, USA

4 Erie Family Health Center, Chicago, IL, USA

5 Center for AIDS Prevention Studies, University of California San Francisco Prevention Research Center, San Francisco, USA disproportionately impacted by HIV. Among all MSM who were diagnosed with HIV in 2016, Latinos accounted for the second highest number (29\%), following African Americans, at a rate of nearly three times that of non-Hispanic Whites [3]. From 2011 to 2015 overall HIV diagnoses among Latino MSM increased 13\% [3]. While it is estimated that $84 \%$ of Latino MSM with HIV are aware of their status, only $49 \%$ are retained in HIV care and $50 \%$ are virally suppressed while the national goal is $>80 \%$ [3]. If current trends persist, one in five Latino MSM will acquire HIV in their lifetime [3].

Latinos accounted for $21 \%$ of new HIV infections in Chicago in 2017 and had a prevalence twice the national rate [4]. Chicago's linkage and retention in care rates are higher than the national rate, at $78 \%$ and $61 \%$ respectively [4]. However, Latino people living with HIV/AIDS (PLWHA) in Chicago continue to struggle with engagement in care relative to their white counterparts; Latino MSM were significantly less likely (17\%) to be retained in care compared to White MSM [4]. As of the 2010 census, Latinos comprise $29 \%$ of the city's population; $80 \%$ of the Latino population is Mexican, accounting for the fourth largest Mexican-origin population in the United States [5]. Among Mexican-American men, low retention-in-care rates are attributable in part 
to structural, financial, and cultural barriers to accessing and remaining in medical care $[1,6]$. These barriers include lack of health insurance, lack of experience navigating the American healthcare system, and a lack of culturally appropriate healthcare facilities $[1,6]$. Their access to HIV primary care is further complicated by HIV-related stigma, homophobia, the U.S. political climate, and the economic reality that men of Mexican descent tend to have less education, fewer economic opportunities and lower incomes [6].

As retention in HIV care is essential to maintain health and viral suppression, innovative interventions to support remaining in care are critical. As part of the Health Resources and Services Administration (HRSA) Special Projects of National Significance (SPNS), the AIDS Foundation of Chicago developed Salud y Orgullo Mexicano (SOM) to identify and re-engage Mexican men who have sex with men who were newly diagnosed with HIV or who have fallen out of HIV care. Here we detail the intervention development.

\section{Methods}

The SOM intervention was developed via a modified Intervention Mapping (IM) process that occurred in four stages [7]. The IM process was modified to ensure adherence to the funding timeline; the team combined some steps (i.e., stage 2 for this project consisted of IM steps 2-3; stage 4 consisted of IM steps 5-6). Intervention Mapping is a standardized iterative approach to developing intervention strategies [7]. Each stage in the IM process comprises several tasks each of which integrates theory; completion of each stage creates a product for the subsequent stage [7]. In stage one a needs assessment was conducted, the design team reviewed the proposed logic model, identified outcomes and objectives and identified existing tools (interventions), in stage two a theoretical model was chosen and programmatic themes were generated by creating matrices of change, in stage three formative work was conducted to inform the intervention design/production, and in stage four an implementation and evaluation plan was created and implemented. Dictated by the funding mechanism, program participation was restricted to Mexican MSM who were either (1) newly diagnosed with HIV and required linkage to HIV care; or (2) living with HIV and not engaged in HIV care in the previous 6 months ("lost to care"). The SOM intervention was developed by adapting components of two established intervention models Antiretroviral Treatment and Access Study (ARTAS) and peer navigation (Project IN-CARE), as well as integrating components of the transnational framework [8]. Further, the intervention was grounded in the stages of change as a theoretical behavior change construct [9]. The intervention design team was multidisciplinary and had expertise in program design, intervention development, and HIV case management. The design team included representation from staff who identify as Latino, bilingual, gay, and living with HIV. The intervention mapping process resulted in an intervention implementation and evaluation plan which was further refined with input from community members.

\section{Results}

\section{Stage 1: Needs Assessment and Problem Analysis}

The needs assessment was partially conducted during the grant writing phase and included a structured literature review, review of epidemiologic data, and discussions with leaders in HIV among Latinos. It was established that Mexican MSM in Chicago have poorer HIV care continuum outcomes compared to White MSM [1, 4, 6]. Dang et al., conducted qualitative research among Latinos which provides insight into the sociocultural and structural barriers to optimal HIV care and help explain the disparity in HIV care continuum outcomes between Mexican and White MSM [4]. The major challenges identified by Dang et al. were HIV stigma, familial and community rejection, and experienced and perceived structural barriers in accessing health care [4].

Upon receiving the grant award, the design team conducted a literature search and a series of staff meetings to identify potential engagement in and/or retention in care interventions. The literature search focused on interventions that were successful both in supporting (re)engagement in HIV-care and had application to the population of focus. Staff meetings consisted of eliciting HIV-specific programs and services known to be available. The design team highlighted strengths, limitations and opportunities of each program/intervention that was identified. Several intervention strategies that were identified were not possible for our team to implement (e.g., provider/clinic level interventions) or were duplicative of services already offered (e.g. transportation assistance) [10]. After reviewing all information available, the interventions selected to inform SOM were ARTAS and project IN-CARE, as these programs were not only found to be effective but also had components that were amenable to adaptation, had evidence of efficacy with racial and ethnic minority MSM, and demonstrated evidence to impact both linkage to and retention in HIV care [11-13].

Of the published interventions to improve retention in care, the strongest evidence comes from the Antiretroviral Treatment and Access Study (ARTAS), which is a strengthsbased case management model to improve linkage and retention in care [13]. Studies have found that ARTAS is a cost efficient, low threshold, effective intervention that can 
be customized to fit the key populations' needs [10, 13]. ARTAS is a manualized intervention that approved as an Effective Behavioral Intervention by the Centers for Disease Control and Prevention. The intervention consists of five sessions; session one is focused on building the relationship between staff delivering the intervention and the client, session two is focused on identifying personal strengths and applying these strengths to obtainable objectives, session three is focused on connecting the client to services, session four is centered on reviewing progress, and session five is a wrap-up session where goals are reviewed and clients are linked to any additional needed services $[10,13]$.

Peer health navigation interventions have also been linked to positive outcomes in improving linkage and retention in HIV care [10]. Project IN-CARE was a locally developed ground-up intervention that consisted of peer navigation for MSM who are racial and ethnic minorities, resulting in 87\% linkage to HIV care over the 5-year project period [11, 12]. The design team included members who both contributed to the development of Project IN-CARE and had experience implementing the intervention. Shared identities and life experience of peers living with HIV function as a means to provide social and emotional support and education to patients $[14,15]$. As HIV-related stigma, homophobia, fear, non-proficiency in the English language, and lack of culturally competent care are often barriers to Mexican men remaining in HIV care, our team prioritized selecting a peer-health model to include in the adaptation process [10, 12-14]. Prior research has shown that Promotores de Salud (peer health workers) are effective at improving healthcare service utilization by Mexican men living with HIV by helping them navigate obstacles to accessing and remaining in HIV care [15-17]. As peers who, like the participants, are Mexican men living with HIV, the Promotores are wellsuited to address structural, financial, personal, and cultural barriers to accessing medical care [6,15-18]. After identifying ARTAS and Project IN-CARE (peer-navigation) as suitable intervention models, the design team developed an intervention curriculum with content that applied to both linkage and retention in HIV care.

The ARTAS session model was used to organize proposed intervention content into five sessions. Further, the design team built in flexibility for individual-level tailored sessions based on participants' needs.

\section{Stage 2: Theoretical Model}

The overall theoretical model for the SOM intervention was the Stages of Change theoretical framework within the transtheoretical model; this model assesses an individual's readiness to act on a new, healthier behavior and provides strategies to guide the individual through various stages of change to the point they are ready to take action and maintain that change $[9,19]$. As such, the strategies of SOM consider each person's current life circumstance and level of need and do not provide a "one-size fits all" approach, considering that within the Stages of Change framework, clients may move through the following stages when deciding whether to participate in HIV medical care: pre-contemplation, contemplation, preparation, action, maintenance, and sometimes relapse $[9,19]$. The Stages of Change framework has been applied in Latino-focused social marketing campaigns and HIV prevention community health worker programs [17, 19]. The transnational framework was also identified as an important framework to include in the intervention development process and was used to adapt existing intervention material for Mexican MSM [8]. Transnationalism was used to describe how Mexican MSM exist in Chicago while simultaneously maintaining connections to Mexico; for SOM transnational practices that were emphasized include communication, travel, and remittances [8]. Further, we considered that participants may be second or third generation immigrants and therefore integrated an assessment of level of transnational identity to tailor the intervention.

\section{Stage 3: Formative Data Collection for Intervention Design and Production}

An advisory board of community experts who work with the Latino community and/or in the HIV field was assembled to inform the intervention development process. The advisory board was comprised of six members representing Mexican men from different organizations including faculty at the University of Illinois at Chicago, the National Latino Commission, Midwest AIDS Training and Education Center and several community-based organizations. The advisory board discussed the proposed intervention components and provided input regarding the needs Mexican MSM living with HIV. Barriers identified by the advisory board were synthesized thematically and informed intervention content creation.

The design team then completed qualitative interviews with "near-peer" participants (e.g., participants similar to the intervention population but ineligible for the program to preserve participant pool for the intervention). "Near-peers" all identified as Mexican MSM and were living with HIV, yet they were ineligible for the program based on being engaged in HIV medical care. Participants $(n=13)$ completed semistructured individual interviews in which they were asked questions about barriers to retention in care, ties to family and Mexico, work, stigma, immigration, and confidentiality concerns. Finally, participants were asked for feedback on the intervention content outline. These interviews were transcribed and coded into themes which guided intervention 
adaptation. The themes were importance of relationships, assistance navigating HIV care, dealing with stigma (HIV and identity-related stigma), and information about dating and sexual relationships. For example, one participant stressed the importance of the peer navigator relationship to a patient who is re-engaging in HIV care: "You need to learn why they stop coming. Explain the results and importance of being on treatment. Really focus. Talk to him [patient], one-on-one, really personal. Figure out what is happening. Form a real true relationship with them." Another participant highlighted the difference between a relationship with a peer navigator and other healthcare providers: "The Promotor needs to be different from the case manager or doctor. The promotor needs to speak Spanish and have my same life experience. So they get me. The case manager or doctor doesn't do this." On the topic of navigating HIV care, one near-peer stated: "I want to learn all services available to me. How to access them. Which are good for me." Stigma and disclosure were discussed by all participants, as one participant discussed community misconceptions and stigma around HIV and requested support around disclosure: "People believed that being HIV-positive means your death is coming soon. They don't understand it or simply don't believe it. Support and sit down and chat with the Promotor to learn about how to tell family and friends my status." Another participant echoed a similar experience of community stigma: "A lot of people they think that everyone who is HIV-positive is gay or that they are going to die real soon. Maybe some focus on teaching the community about it. Teaching the community the truth about HIV." Finally, participants reported they wanted support managing relationships and dating, specifically information about navigating HIV prevention with serodiscordant partners: "Simple information like about PrEP and what treatment as prevention is; to stay healthy while I'm seeing someone for them to stay healthy. For HIV not to be the only thing that is about me;" and another participant reported: "I'd talk about someone who doesn't have HIV how to like be with them and tell them that they won't have HIV." Following the themes from the qualitative interviews, the intervention components were further developed to emphasize the relationship between the peer health educator and the intervention participant; session content was revised to allow the peer health navigator to share more about his own life experience regarding his HIV diagnosis; navigating HIV care and treatment; disclosing to family members and friends; and engaging in relationships, sex, and dating.

Transnational themes were identified, developed and incorporated into the intervention content by the design team and included: (1) assessing a participant's level of transnational identity and cross-border practices and determining to what degree that shapes his retention in care; (2) navigating cost-effective HIV care and seeking supportive services, given the added expense of remittances; (3) determining how and when to disclose HIV status and seek social support from family and friends in their country of origin and in the U.S.; (4) providing social support through peer health workers; (5) guiding participants through adapting to the U.S. HIV health care system model; and (6) addressing cultural norms that might shape a participant's engagement in healthcare, including machismo, familismo, and fatalism [8]. Machismo refers to a pride in and responsibility towards identifying with and displaying traditional, often dominant, masculinity. This can influence men's perception of their sexuality and their willingness to engage care. Familismo is a strong orientation and commitment towards the family in Latino culture, especially as it relates to marriage, childbearing, and familial obligation. Finally, the concept of fatalismo is a sense of powerlessness to effect change or resignation to a perceived inevitability that might prevent some Mexican MSM from seeking HIV care. Discussion of each of these cultural norms as they may apply to the intervention participants' lives and influence their engagement in care are included in the content of the SOM intervention and are stressed in relationship building between the peer and participant.

\section{Stage 4: Implementation and Evaluation Plan}

The implementation plan consisted of the manualized program procedures, standardized intervention content, and promotor training content. Multiple internal staff at the AIDS Foundation of Chicago and from HRSA SPNS reviewed and provided editing support to the implementation plan. Peer health navigators or Promotores should identify as Mexican, gay or bisexual, be bilingual English/Spanish, and be living with HIV. We proposed that Promotores have a participant load ratio of 25:1, which is half the standard rate of Ryan White HIV case management. Promotores will complete a standardized training which consists of reviewing and role-playing the curriculum with the project director and completed trainings on ethics, boundaries, and relationship building. The training will be given prior to engaging with participants and Promotores will have opportunities for booster training sessions with the project director. The SOM intervention was designed to be implemented in partnership with a Latino-serving federally qualified health center (FQHC), where participants will be recruited and will complete the intervention sessions. Staff at this health center are bilingual in English/Spanish and have a longstanding history in the community of serving Latinos. Further, the FQHC is experienced in providing HIV care to MSM.

The evaluation plan consisted of data collection for a cross-site evaluation coordinated by the Evaluation and 
Technical Assistance Center (ETAC) at University of California San Francisco. The ETAC also provided review and input on local site evaluation monitoring and evaluation plans. The implementation and evaluation of the project will be reported elsewhere.

The Salud y Orgullo Mexicano intervention is an individual level peer-based intervention that is comprised of a series of five standardized educational sessions, as well as tailored one-on-one sessions to support participants' individual needs (see Table 1). Each of the five sessions includes one vignette that is based on peer navigator's composite life experiences and are centered on themes that emerged from the near-peer qualitative interviews. These vignettes were designed as conversation starters and relationship builders; the vignettes are also related to the content of the sessions, have transnational themes woven through them, and serve as a method to reinforce and personalize intervention content.

\section{Intervention Description}

\section{Discussion}

SOM was developed as an individual-level peer navigation intervention to support linkage and retention in HIV care for Mexican MSM living with HIV in Chicago. Using a modified intervention mapping process, the design team successfully developed a standardized intervention consisting of a detailed manual and operating procedures to assist with implementation of the intervention. To our knowledge, SOM is the only peer navigation intervention designed to support Mexican MSM living with HIV in Chicago. SOM is culturally specific and includes transnational themes, as recommended by Meyer et al. who stressed the importance of incorporating protective factors into HIV-specific initiatives for Mexican MSM [20]. Very few interventions exist that focus on HIV care (linkage and/or retention) for Latinos; we identified only two such interventions in the literature. Of note, neither intervention was designed specifically for

Table 1 SOM intervention session overview

\begin{tabular}{|c|c|c|}
\hline Determinants: Change objectives & Session content & Example method and application \\
\hline $\begin{array}{l}\text { Knowledge: Describe HIV transmission and } \\
\text { viral life cycle }\end{array}$ & $\begin{array}{l}\text { Session one } \\
\text { HIV } 101 \text { (transmission and viral life cycle) }\end{array}$ & $\begin{array}{l}\text { Information transfer: quizzes; games } \\
\text { Guided practice: role plays }\end{array}$ \\
\hline $\begin{array}{l}\text { Skills: Demonstrate strategies to improve } \\
\text { appointment adherence }\end{array}$ & $\begin{array}{l}\text { Importance of primary care } \\
\text { Strategies to improve appointment adherence }\end{array}$ & \\
\hline $\begin{array}{l}\text { Self-efficacy: Express confidence in talking to } \\
\text { a doctor/medical provider }\end{array}$ & $\begin{array}{l}\text { Strategies for how to talk to doctor/medical } \\
\text { provider }\end{array}$ & \\
\hline $\begin{array}{l}\text { Knowledge: Explain how HIV medication } \\
\text { impacts viral suppression }\end{array}$ & $\begin{array}{l}\text { Session two } \\
\text { Medication readiness assessment }\end{array}$ & $\begin{array}{l}\text { Information transfer: assessment review } \\
\text { Modeling: Promotores beliefs on medication }\end{array}$ \\
\hline $\begin{array}{l}\text { Normative beliefs: Recognize how medication } \\
\text { beliefs impacts adherence }\end{array}$ & $\begin{array}{l}\text { Medication adherence assessment } \\
\text { How HIV medications act against the virus } \\
\text { Medication beliefs discussion }\end{array}$ & \\
\hline $\begin{array}{l}\text { Knowledge: Describe lab value key terms and } \\
\text { definitions; Explain comorbidity impact on } \\
\text { living with HIV } \\
\text { Skills: Demonstrate ability to track lab values }\end{array}$ & $\begin{array}{l}\text { Session three } \\
\text { Understanding lab values } \\
\text { Tracking lab values and impact on health } \\
\text { Discussion of co-morbid conditions }\end{array}$ & $\begin{array}{l}\text { Information transfer: teach back on lab values; } \\
\text { game for tracking values }\end{array}$ \\
\hline $\begin{array}{l}\text { Knowledge: Summarize impact of STIs on } \\
\text { HIV } \\
\text { Attitudes: Express importance of understand- } \\
\text { ing HIV risk behaviors and risk reduction } \\
\text { strategies }\end{array}$ & $\begin{array}{l}\text { Session four } \\
\text { Assessment of HIV risk behaviors } \\
\text { HIV risk reduction } \\
\text { Impact of STI's and HIV disease }\end{array}$ & $\begin{array}{l}\text { Information transfer: assessment review } \\
\text { Anticipated behavior: reflection and discussion }\end{array}$ \\
\hline $\begin{array}{l}\text { Skills: Determine safety in disclosure situa- } \\
\text { tions; Describe HIV care plan in Mexico }\end{array}$ & $\begin{array}{l}\text { Session five } \\
\text { Disclosure }\end{array}$ & $\begin{array}{l}\text { Guided practice: demonstrations; disclosure } \\
\text { role play }\end{array}$ \\
\hline $\begin{array}{l}\text { Self-efficacy: Express confidence in coping } \\
\text { with stigma and identifying social supports }\end{array}$ & $\begin{array}{l}\text { Social support assessment } \\
\text { Coping with stigma }\end{array}$ & Information transfer: quiz; assessment review \\
\hline $\begin{array}{l}\text { Knowledge: Describe immigration and citizen- } \\
\text { ship policies; Explain strategies to maintain } \\
\text { HIV care while in Mexico }\end{array}$ & $\begin{array}{l}\text { Maintaining your care while traveling to } \\
\text { Mexico } \\
\text { Immigration and citizenship }\end{array}$ & \\
\hline $\begin{array}{l}\text { Attitudes } \\
\text { Skills } \\
\text { Self-efficacy } \\
\text { Knowledge }\end{array}$ & $\begin{array}{l}\text { Individual level sessions } \\
\text { Content to be determined by peer }\end{array}$ & $\begin{array}{l}\text { Anticipated behavior } \\
\text { Modeling } \\
\text { Guided practice }\end{array}$ \\
\hline
\end{tabular}


Mexican MSM rather they were for Latinos living with HIV $[21,22]$. The first intervention delivered a 5-week instructional program to Spanish-speaking Latinos and found an intervention effect on healthy literacy and quality of patient/ provider relationship compared to the control group [21]. The second intervention focused on Latinos living on the U.S.-Mexico border and utilized cognitive behavioral therapy to promote medication adherence [22]. The SOM intervention includes skill building and guided practice to improve health literacy and support medication adherence. Further the SOM intervention provides participants with the opportunity to have a relationship with a peer navigator who is more capable of relating to life circumstances compared to a medical provider.

One limitation of the intervention design process was the use of near peers to inform the content. As the near peers were retained in HIV care they may differ in non-measured ways compared to participants who have fallen out of care or are newly diagnosed with HIV.

\section{Conclusion}

Our team developed an innovative peer health intervention to support retention in care for Mexican MSM living with HIV in Chicago using intervention mapping. Further implementation and evaluation should be conducted to determine the feasibility, acceptability, and initial efficacy of the designed intervention on HIV health outcomes among Mexican MSM living with HIV in Chicago.

Funding The funding was provided by Health Resources and Services Administration (Grant No. H97HA26498).

Open Access This article is licensed under a Creative Commons Attribution 4.0 International License, which permits use, sharing, adaptation, distribution and reproduction in any medium or format, as long as you give appropriate credit to the original author(s) and the source, provide a link to the Creative Commons licence, and indicate if changes were made. The images or other third party material in this article are included in the article's Creative Commons licence, unless indicated otherwise in a credit line to the material. If material is not included in the article's Creative Commons licence and your intended use is not permitted by statutory regulation or exceeds the permitted use, you will need to obtain permission directly from the copyright holder. To view a copy of this licence, visit http://creativecommons.org/licenses/by/4.0/.

\section{References}

1. Gant Z, Bradley H, Hu X, Skarbinski J, Hall HI, Lansky A. Hispanics or Latinos living with diagnosed HIV: progress along the continuum of HIV care-United States, 2010. MMWR Morb Mortal Wkly Rep. 2014;63(40):886.

2. Gray KM, Valverde EE, Tang T, Siddiqi AE, Hall HI. Diagnoses and prevalence of HIV infection among Hispanics or Latinos-United States, 2008-2013. Morb Mortal Wkly Rep. 2015;64(39):1097-103.

3. Centers for Disease Control and Prevention. HIV and Hispanic/ Latino Gay and Bisexual Men. 2019. Available from https://www. cdc.gov/hiv/group/msm/hispanic-latino.html. Accessed Oct 2019.

4. Chicago Department of Public Health. STI/HIV surveillance report, 2017. Chicago, IL: City of Chicago

5. U.S. Census Bureau. Population estimates 2019, https://www. census.gov/quickfacts/chicagocityillinois. Accessed Feb 2021.

6. Dang BN, Giordano TP, Kim JH. Sociocultural and structural barriers to care among undocumented Latino immigrants with HIV infection. J Immigr Minor Health. 2012;14(1):124-31.

7. Eldredge L, et al. Planning health promotion programs: an intervention mapping approach. John Wiley and Sons, 2016.

8. Sauceda John A, et al. From theory to application: a description of transnationalism in culturally-appropriate HIV interventions of outreach, access, and retention among Latino/a populations. J Immigr Minor Health, 2019: 332-345.

9. Prochaska JO, DiClemente CC. Transtheoretical therapy: towards a more integrative model of change. Psychotherapy Theory Res Pract. 1982;19:278-88.

10. Higa DH, et al. Interventions to improve retention in HIV primary care: a systematic review of US studies. Curr HIV/AIDS Rep. 2012;9(4):313-25.

11. Maulsby $\mathrm{C}$, et al. Positive charge: filling the gaps in the US HIV continuum of care. AIDS Behav. 2015;19(11):2097-107.

12. Kim J, et al. Cost and threshold analysis of positive charge, a multi-site linkage to HIV care program in the United States. AIDS Behav. 2015;19(10):1735-41.

13. Gardner LI, et al. Psychological and behavioral correlates of entering care for HIV infection: the antiretroviral treatment access study (ARTAS). AIDS Patient Care STDS. 2007;21(6):418-25.

14. Pagkas-Bather J, Jaramillo J, Henry J, Grandberry V, Ramirez LF, Cervantes L, Stekler JD, Andrasik MP, Graham SM. What's PrEP?: peer navigator acceptability among minority MSM in Washington. BMC Public Health. 2020;20(1):1-2.

15. Hallum-Montes R, et al. Linking peers, patients, and providers: a qualitative study of a peer integration program for hard-to-reach patients living with HIV/AIDS. AIDS Care. 2013;25(8):968-72.

16. Genberg BL, et al. Improving engagement in the HIV care cascade: a systematic review of interventions involving people living with HIV/AIDS as peers. AIDS Behav. 2016;20(10):2452-63.

17. Rios-Ellis B, Becker D, Espinoza L, Nguyen-Rodriguez S, Diaz G, Carricchi A, Galvez G, Garcia M. Evaluation of a community health worker intervention to reduce HIV/AIDS stigma and increase HIV testing among underserved Latinos in the Southwestern US. Public Health Rep. 2015;130(5):458-67.

18. Hacker K, Anies M, Folb BL, Zallman L. Barriers to health care for undocumented immigrants: a literature review. Risk Manag Healthcare Policy. 2015;8:175.

19. Norcross JC, et al. Stages of change. J Clin Psychol. 2011;67(2):143-54.

20. Meyer MA, Champion JD. Protective factors for HIV infection among Mexican American men who have sex with men. J Assoc Nurses AIDS Care. 2010;21(1):53-62.

21. Van Servellen G, Nyamathi A, Carpio F, et al. Effects of a treatment adherence enhancement program on health literacy, patient-provider relationships, and adherence to HAART among 
low-income HIV-positive Spanish-speaking Latinos. AIDS Patient Care STDS. 2005;19(11):745-59.

22. Simoni JM, Wiebe JS, Sauceda JA, Huh D, Sanchez G, Longoria V, Bedoya CA, Safren SA. A preliminary RCT of CBT$\mathrm{AD}$ for adherence and depression among HIV-positive Latinos on the US-Mexico border: the Nuevo Dia study. AIDS Behav. 2013;17(8):2816-29.

Publisher's Note Springer Nature remains neutral with regard to jurisdictional claims in published maps and institutional affiliations. 